\title{
Clinical applicability of nursing outcomes in the evolution of orthopedic patients with Impaired Physical Mobility ${ }^{1}$
}

\author{
Marcos Barragan da Silva² \\ Miriam de Abreu Almeida ${ }^{3}$ \\ Bruna Paulsen Panato 4 \\ Ana Paula de Oliveira Siqueira ${ }^{5}$ \\ Mariana Palma da Silva ${ }^{4}$ \\ Letícia Reisderfer ${ }^{4}$
}

\begin{abstract}
Aim: to evaluate the clinical applicability of outcomes, according to the Nursing Outcomes Classification (NOC) in the evolution of orthopedic patients with Impaired Physical Mobility Method: longitudinal study conducted in 2012 in a university hospital, with 21 patients undergoing Total Hip Arthroplasty, evaluated daily by pairs of trained data collectors. Data were collected using an instrument containing five Nursing Outcomes, 16 clinical indicators and a five point Likert scale, and statistically analyzed. Results: The outcomes Body Positioning: self-initiated, Mobility, Knowledge: prescribed activity, and Fall Prevention Behavior presented significant increases in mean scores when comparing the first and final evaluations $(p<0.001)$ and $(p=0.035)$. Conclusion: the use of the NOC outcomes makes it possible to demonstrate the clinical progression of orthopedic patients with Impaired Physical Mobility, as well as its applicability in this context.
\end{abstract}

Descriptors: Nursing Diagnosis; Nursing Process; Classification; Outcome Assessment (Health Care); Orthopaedic Nursing.

\footnotetext{
${ }^{1}$ Paper extracted from master's thesis "Clinical applicability of the nursing outcomes in patients with impaired physical mobility undergoing to total hip replacement" presented to Universidade Federal do Rio Grande do Sul, Porto Alegre, RS, Brazil. Supported by Fundo de Incentivo à Pesquisa do Hospital de Clínicas de Porto Alegre (FIPE), Brazil, process \# 11-0601 and by Conselho Nacional de Desenvolvimento Científico Tecnológico (CNPq), Brazil, process \# 479884/2012-9.

2 Doctoral student, Escola de Enfermagem, Universidade Federal do Rio Grande do Sul, Porto Alegre, RS, Brazil.

${ }^{3} \mathrm{PhD}$, Associate Professor, Escola de Enfermagem, Universidade Federal do Rio Grande do Sul, Porto Alegre, RS, Brazil.

${ }^{4}$ Undergraduate student in Nursing, Escola de Enfermagem, Universidade Federal do Rio Grande do Sul, Porto Alegre, RS, Brazil.

5 Master's student, Escola de Enfermagem, Universidade Federal do Rio Grande do Sul, Porto Alegre, RS, Brazil.
}

Corresponding Author:

Miriam de Abreu Almeida

Rua Vicente da Fontoura, 3008/202

Bairro: Rio Branco

CEP: 90640-002, Porto Alegre, RS, Brasil

E-mail: miriam.abreu2@gmail.com
Copyright () 2015 Revista Latino-Americana de Enfermagem This is an Open Access article distributed under the terms of the Creative Commons Attribution Non-Commercial License (CC BY-NC).

This license lets others distribute, remix, tweak, and build upon your work non-commercially, and although their new works must also acknowledge you and be non-commercial, they don't have to license their derivative works on the same terms. 


\section{Introduction}

With longer life expectancy and the consequent increase in the number of active and independent elderly people, the surgical replacement of the hip joints are procedures increasingly used in the population with orthopedic problems ${ }^{(1-2)}$. The indication of Total Hip Arthroplasty (THA) should be based on the failure of conservative treatment and on the justifiable clinical condition(1-2). Total Hip Arthroplasty is a widely used and effective procedure that improves the quality of life of patients by increasing functional capacity, decreasing pain and improving coxofemoral function ${ }^{(1-2)}$. In Brazil, this surgery was one of the most performed in the Brazilian National Health System (SUS) over the previous two years(3).

Much of the post-operative care, essential to the success of the surgical procedure, is the responsibility of the nurse and is directed toward the correct mobilization and education of the patient ${ }^{(4)}$. Therefore, these patients require more nursing care time, as they become dependent in the postoperative period, mainly due to mobility limitations and confinement to the bed. In spite of different interventions being carried out, the measurement of Nursing Outcomes is still new in Brazilian Nursing(5). In this sense, to obtain desired outcomes it is necessary to establish accurate diagnoses, goals to be achieved and interventions that enable the improvement of the patient ${ }^{(5)}$.

The Nursing Outcomes Classification (NOC) was developed in order to standardize the nursing language related to the evaluation of outcomes. This classification is structured on three levels of abstraction, including Nursing Outcomes, indicators and Likert scales. The NOC aims to evaluate the progress, stagnation or worsening of the clinical condition of the patient, allowing the verification of the progress, especially as a result of the interventions prescribed and implemented by the Nurse $^{(6)}$. Its interconnection with classifications used in the Diagnosis( ${ }^{(7)}$ and Nursing Interventions ${ }^{(8)}$ improves clinical decision making in patient care and in monitoring the progress.

In patients who underwent THA, the Nursing Diagnosis Impaired Physical Mobility(7) (IPM), has been highlighted as prevalent ${ }^{(9)}$. However, the clinical progression of the patient with this diagnosis, using a standardized classification, remains unexplored.

In recent years, there has been an increase in the production of studies focused on the NOC. A systematic review identified 312 articles about standardized language, with the majority of studies about the NOC focused on the reliability and validity of its terms $(n=12)$ and the perception of nurses regarding the potential for its use in practice $(n=12)$. However, only six studies used this classification in clinical nursing practice ${ }^{(10)}$.

The present investigation was outlined from these considerations. The relevance of this study lies in the visibility that it can give to the clinical progression of the patient, through the use of a standardized classification. It is believed that the changes in mobility achieved by the patient may support the development of more effective care. Thus, the aim of this study was to evaluate the clinical applicability of outcomes, according to the NOC, in the progression of orthopedic patients with impaired physical mobility.

\section{Methods}

This longitudinal study was conducted in a large university hospital in southern Brazil, accredited by the Joint Commission International. The institution has 865 beds, distributed over more than 60 specialties. The Nursing Process, used as a working method, is computerized and has the nursing diagnosis (ND) step based on the terminology of NANDA International(7) and the prescribed care based on the Nursing Interventions Classification (NIC) ${ }^{(8)}$.

The study population consisted of patients in the THA postoperative period, hospitalized in the Surgical Nursing Service units. The sample size calculation was estimated for the improvement of the NOC score result, using the WinPepi Version 10.5 program. Considering a difference of 0.5 in the score of the results of the NOC, obtained in a pilot study, with a power of $90 \%$ and an alpha type error of $1 \%$, it would be necessary to include 17 patients in the study, with $20 \%$ added due to possible monitoring period losses.

The consecutive type sample was selected by convenience, so that the patients were allocated in the study by admission in the units. The inclusion criteria considered were patients aged $\geq 18$ years who underwent THA; with the IPM nursing diagnosis established by the attending nurse and recorded in the medical record; and that remained hospitalized for four days, or until discharge. This monitoring period was chosen, considering the length of hospitalization. Patients were excluded that presented clinical instability during the data collection period; were transferred to other institutions or units, or that presented limitations that prevented communication and interaction with the researchers. 
For the selection of the Nursing Outcomes, 44 results were considered, according to the NOC-NANDA-I linkage, including suggested and additional associated outcomes for the IPM diagnosis(6). These outcomes were evaluated by three nurses with three or more years of clinical experience in the care of orthopedic patients. Thus, considering the title and the definition of each of the outcomes and indicators, the nurses noted the options recommend or not recommend for the evaluation of the diagnosis studied. Through the consensus, five Nursing Outcomes and 16 indicators were listed for their clinical applicability to be verified. The NOC recommendation regarding the choice of outcomes relevant to the care context in which they will be applied was taken into consideration $^{(6)}$.

After this step, the data collection instrument was constructed. It contained sociodemographic and clinical variables, the five Nursing Outcomes and the 16 indicators with conceptual and operational definitions developed by the researchers from a literature review. The outcomes evaluated are presented in Figure 1.

\begin{tabular}{|c|c|c|c|}
\hline Domains & Suggested outcomes & Indicators & Scales \\
\hline Functional Health & (0203) Body Positioning: self-initiated & $\begin{array}{l}\text { (020302) Moves from lying to sitting } \\
(020304) \text { Moves from sitting to standing } \\
(020305) \text { Moves from standing to sitting. } \\
(020303) \text { Moves from sitting for lying. }\end{array}$ & $\begin{array}{l}\text { Severely compromised to Not } \\
\text { compromised }\end{array}$ \\
\hline \multirow[t]{2}{*}{ Functional Health } & (0208) Mobility & (020806) Walking. & $\begin{array}{l}\text { Severely compromised to Not } \\
\text { compromised }\end{array}$ \\
\hline & Additional associated outcomes & & \\
\hline Perceived Health & (2102) Pain Level & (210201) Reported pain & Severe to None \\
\hline $\begin{array}{l}\text { Health Knowledge and } \\
\text { Behavior }\end{array}$ & (1811) Knowledge: prescribed activity & $\begin{array}{l}\text { (181104) Prescribed activity restrictions } \\
(181116) \text { Strategies to safely ambulate } \\
\text { (181112) Proper performance of prescribed } \\
\text { activity } \\
(181120) \text { Benefits of prescribed activity }\end{array}$ & $\begin{array}{l}\text { No knowledge to Extensive } \\
\text { knowledge }\end{array}$ \\
\hline $\begin{array}{l}\text { Health Knowledge and } \\
\text { Behavior }\end{array}$ & (1909) Fall prevention behavior & $\begin{array}{l}\text { (190910) Uses well-fitting tied shoes } \\
\text { (190901) Uses assistive devices correctly } \\
\text { (190902) Requests assistance with mobility }\end{array}$ & $\begin{array}{l}\text { Never demonstrated to } \\
\text { Consistently demonstrated }\end{array}$ \\
\hline
\end{tabular}

Figure 1 - Domains, Nursing Outcomes and their indicators listed for the diagnosis of IPM in THA patients. Porto Alegre, RS, Brazil, 2013.

The nurses that selected the outcomes and indicators validated the content and appearance of the instrument. Small suggestions were incorporated. The instrument was tested in a pilot study with four patients, in order to observe the variation of the indicator scores, to standardize the data collection logistics, and to support the performance of the sample calculation. It should be noted that the patients evaluated in the pilot study were not included in the final sample and the measurement scales were maintained in accordance with the NOC.

Data collection was performed by undergraduate research students that were members of a research group related to the NANDA-I nursing classifications, NIC and NOC. They underwent 18-hours of training, including theoretic lectures on the THA postoperative period and discussion of clinical cases of patients undergoing this surgery, with IPM, as well as a review of the instruments and data collection logistics.

Data were collected between August and December 2012. The logistics began with the recruitment of patients in the inpatient units. After signing the consent form, the patients were monitored with daily evaluations.
Two collectors evaluated the patient simultaneously, although independently, recording the data in individual instruments. For the evaluation of the results, data from medical records, interviews and physical examinations were used, according to the conceptual and operational definitions developed for the selected clinical indicators. These indicators were evaluated by means of a five point Likert scale, where 1 corresponded to the worst score and 5 the best score, with different measurement scales of the NOC.

The Excel 2010 software was used for the construction of the data sheets, and the Statistical Package for the Social Sciences (SPSS) version 18.0 for the data analysis.The continuous variables were expressed as mean and standard deviation for those with normal distribution or median and interquartile range for the asymmetrical variables. Categorical variables were expressed as percentages and absolute numbers. The Student's t-test for paired samples was used to compare the means between the collectors and between the first and last days of evaluation. A value of $p<0.05$ was considered significant. 
The study was approved by the Research Ethics Committee of the Institution, under authorization No. 110601.

\section{Results}

The study included 21 patients, who received 68 reviews, with 15 (71.4\%) of them evaluated over a fourday monitoring period, and the others over three days, according to the length of hospital stay.

Of the patients monitored, the majority were female with a mean age of $58.8( \pm 16.7)$ and 15 of them (71.4\%) underwent primary THA. Osteoarthritis was the basal disease in the majority of cases, as shown in Table 1.

Table 1 - Socio-demographic and clinical characteristics of the patients undergoing THA. Porto Alegre, RS, Brazil, 2013.

\begin{tabular}{|c|c|}
\hline Variable & Total $\mathrm{n}=\mathbf{2 1}$ \\
\hline Age, years* & $58.8( \pm 16.7)$ \\
\hline Gender, female $^{\dagger}$ & $13(61.9)$ \\
\hline $\operatorname{BMI}\left(\mathrm{kg} / \mathrm{m}^{2}\right)^{*}$ & $23.01( \pm 7.09)$ \\
\hline Schooling, years* & $8.2( \pm 4.1)$ \\
\hline Caregiver presence on admission ${ }^{\dagger}$ & $17(80.9)$ \\
\hline \multicolumn{2}{|l|}{ Reason for surgical indication } \\
\hline Osteoarthritis $^{\dagger}$ & $16(76.2)$ \\
\hline Dislocation $^{\dagger}$ & $3(14.2)$ \\
\hline Fractures $^{\dagger}$ & $2(9.5)$ \\
\hline Primary $\mathrm{THA}^{\dagger}$ & $15(71.4)$ \\
\hline $\begin{array}{l}\text { Performed preoperative outpatient nursing } \\
\text { consultation }^{\dagger}\end{array}$ & $5(23.8)$ \\
\hline Received preoperative nursing home visits ${ }^{\dagger}$ & $4(19)$ \\
\hline Presence of pain in the hip prior to surgery ${ }^{\dagger}$ & $20(95.2)$ \\
\hline Suffered a fall in the previous year ${ }^{\dagger}$ & $10(47.6)$ \\
\hline Evaluation time, 4 days $^{\dagger}$ & $15(71.4)$ \\
\hline
\end{tabular}

*Numbers expressed as mean ( \pm standard deviation) $+\mathrm{n}(\%)$
The Nursing Outcomes were measured daily, according to the clinical progression of the patients. Regarding their mean scores presented, there was a significant increase in scores in almost all evaluations, with the exception of Pain Level $(p=0.265)$, as shown in Table 2.

Regarding the clinical evolution, the temporal curves show the differences in the scores of the scales of the NOC outcomes for each day evaluated. As can be seen in Figure 2, an increase was verified in virtually all evaluations.

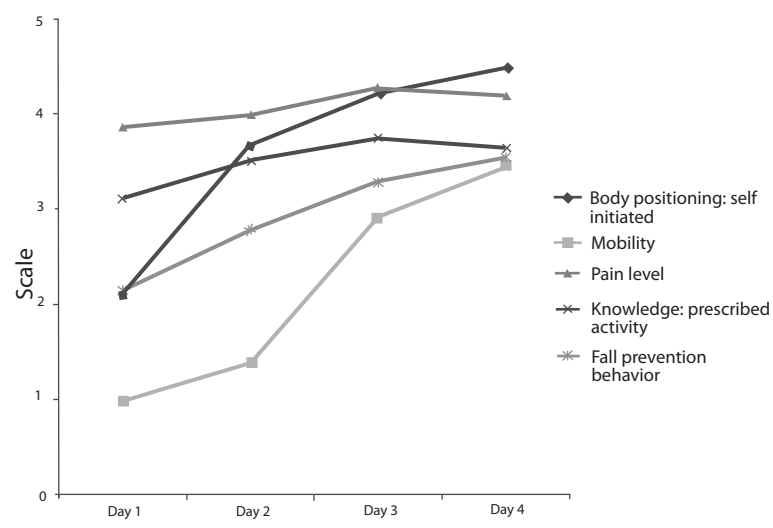

Figure 2 - Temporal curves for the Nursing Outcomes in patients with IPM undergoing THA. Porto Alegre, RS, Brazil, 2013.

In the comparison between the mean scores of the first and last evaluations of the patients, no significant difference was observed in the measurements of the collectors. The mean difference was no more than 0.35 points in any of the parameters analyzed, as shown in Table 3.

Table 2 - Mean scores of the Nursing Outcomes for patients with IPM ND undergoing THA. Porto Alegre, RS, Brazil, 2013.

\begin{tabular}{|c|c|c|c|c|c|}
\hline & $1^{\text {st }}$ Day & $2^{\text {nd }}$ Day & $3^{\text {rd }}$ Day & $4^{\text {th }}$ Day & \\
\hline Nursing Outcomes & $\begin{array}{c}\text { Mean ( } \pm \text { Standard } \\
\text { Deviation) }\end{array}$ & $\begin{array}{c}\text { Mean ( } \pm \text { Standard } \\
\text { Deviation) }\end{array}$ & $\begin{array}{c}\text { Mean ( } \pm \text { Standard } \\
\text { Deviation) }\end{array}$ & $\begin{array}{c}\text { Mean ( } \pm \text { Standard } \\
\text { Deviation) }\end{array}$ & $\mathbf{p}^{*}$ \\
\hline Body positioning: self-initiated & $2.10( \pm 1.47)$ & $3.68( \pm 1.20)$ & $4.23( \pm 1.00)$ & $4.48( \pm 0.99)$ & $<0.001$ \\
\hline Mobility & $1.00( \pm 0.00)$ & 1. $40( \pm 1.06)$ & $2.93( \pm 1.67)$ & $3.47( \pm 1.36)$ & $<0.001$ \\
\hline Pain level & $3.87( \pm 0.99)$ & $4.00( \pm 0.93)$ & $4.27( \pm 0.96)$ & $4.20( \pm 1.27)$ & 0.265 \\
\hline Knowledge: prescribed activity & $3.12( \pm 0.51)$ & $3.52( \pm 0.55)$ & $3.75( \pm 0.39)$ & $3.64( \pm 0.56)$ & 0.035 \\
\hline Fall prevention behavior & $2.15( \pm 0.72)$ & $2.78( \pm 0.77)$ & $3.29( \pm 0.75)$ & $3.55( \pm 0.56)$ & $<0.001$ \\
\hline
\end{tabular}

* Paired student's t-test 
Table 3 - Comparison of the mean scores of the NOC Nursing Outcomes between the evaluators of the patients with IPM ND undergoing THA. Porto Alegre, RS, Brazil, 2013.

\begin{tabular}{|c|c|c|c|c|c|}
\hline \multirow[b]{2}{*}{ Outcomes } & \multirow[b]{2}{*}{$\mathbf{N}$} & Evaluator 1 & Evaluator 2 & \multirow[b]{2}{*}{ Difference (Cl 95\%) } & \multirow[b]{2}{*}{$\mathbf{p}^{*}$} \\
\hline & & $\begin{array}{c}\text { Mean ( } \pm \text { Standard } \\
\text { Deviation) }\end{array}$ & $\begin{array}{c}\text { Mean ( } \pm \text { Standard } \\
\text { Deviation) }\end{array}$ & & \\
\hline \multirow[t]{2}{*}{ Body positioning: self-initiated } & 21 & $1.79( \pm 1.33)$ & $1.81( \pm 1.38)$ & $0.02(-0.02-0.07)$ & 0.329 \\
\hline & 15 & $4.48( \pm 0.99)$ & $4.38( \pm 0.96)$ & $0.10(-0.01-0.21)$ & 0.082 \\
\hline \multirow[t]{2}{*}{ Mobility } & 21 & $1.00( \pm 0.00)$ & $1.00( \pm 0.00)$ & $0.00(0.00-0.00)$ & 1.000 \\
\hline & 15 & $3.47( \pm 1.36)$ & $3.40( \pm 1.35)$ & $0.07(-0.08-0.21)$ & 0.334 \\
\hline \multirow[t]{2}{*}{ Pain level } & 21 & $3.76( \pm 1.22)$ & $3.76( \pm 1.22)$ & $0.00(0.00-0.00)$ & 1.000 \\
\hline & 15 & $4.20( \pm 1.27)$ & $4.13( \pm 1.06)$ & $0.07(-0.19-0.32)$ & 0.582 \\
\hline \multirow[t]{2}{*}{ Knowledge: prescribed activity } & 21 & $3.12( \pm 0.53)$ & $3.05( \pm 0.65)$ & $0.07(-0.06-0.21)$ & 0.284 \\
\hline & 15 & $3.64( \pm 0.56)$ & $3.57( \pm 0.50)$ & $0.07(-0.16-0.31)$ & 0.515 \\
\hline \multirow[t]{2}{*}{ Fall prevention behavior } & 21 & $2.28( \pm 0.69)$ & $2.41( \pm 0.89)$ & $0.13(-0.08-0.33)$ & 0.210 \\
\hline & 15 & $3.55( \pm 0.56)$ & $3.58( \pm 0.61)$ & $0.02(-0.15-0.20)$ & 0.788 \\
\hline
\end{tabular}

* Paired student's t-test

\section{Discussion}

This study monitored 21 patients with IPM in the THA postoperative period, aiming to verify the clinical applicability of five Nursing Outcomes contained in the Functional Health, Perceived Health, and Health Knowledge and Behavior domains ${ }^{(6)}$. It should be noted that the study did not aim to evaluate the validity of the NOC scales, but the applicability of this classification in clinical practice, observing the changes of the health status of patients with the progression of the nursing care.

Regarding the Body Positioning: self-initiated Outcome, this showed a progressive increase in the mean scores of the indicators evaluated in the daily monitoring of the patients. It should be noted that the mean scores identified by the examiners did not present statistically significant differences, demonstrating consistency in the evaluations. For patients who have undergone THA it is recommended that the legs are kept abducted and with hip flexion greater than $90^{\circ}$, in order to prevent displacement of the prosthesis ${ }^{(11)}$. They are informed about the need for correct positioning in all the movements performed. These guidelines are contained in a clinical protocol and support nurses in the safe handling of these patients, facilitating the management of the positioning during care activities ${ }^{(12)}$.

The clinical improvements in the Body Positioning: self-initiated Outcome and the Mobility Outcome, which also presented a significant improvement in the mean scores $(p<0.001)$, were also found the literature, as mobility is a term that has been used to explain a series of functional activities, including transfer from the bed to the chair and walking ${ }^{(13)}$. The operational definitions of these outcomes included, for example, whether the patient maintained the proper positioning to sit on the bed, or when transferring from the bed to a chair, or vice versa; whether the patient started the first step with the operated limb; whether they kept the leg straight, distributed the weight with crutches or a walking frame; and important nursing care to be evaluated during the movement of these patients ${ }^{(11)}$. In addition to these evaluations, the degree of impairment of the Nursing Diagnosis under study can be perceived by measuring the Nursing Outcomes, which gradually improved over the days of monitoring.

It was observed that the study sample presented a mean body mass index (BMI) of $23.01 \mathrm{~kg} / \mathrm{m}^{2}$ ( \pm 7.09$)$, which indicates normal weight. This data may have influenced the improvement of Mobility, supported by the research findings that showed the BMI to be a predictor for the outcomes of the THA ${ }^{(14)}$.

The Pain Level Nursing Outcome $(p=0.265)$ showed no statistically significant difference, with the mean scores between the collectors being excellent in the first evaluation and, in the last, the variation was only 0.07 in the Reported Pain indicator scores. In the study setting, pain is evaluated as the fifth vital sign; thus, it is believed that the data can be related to the greater attention given to patients with the possibility of acute pain(15).

Pain is a subjective phenomenon of extremely complex perception. As a factor related to the IPM diagnosis, patients who will have a hip prosthesis fitted learn to live with pain in their daily activities and not seek help until it becomes unbearable(16). The algic perception was present in 20 (95.2\%) patients prior to 
the surgery. Accordingly, it can be inferred that the pain was higher in the period leading up to the surgery, when compared to the postoperative period(16).

Regarding the Knowledge: prescribed activity Outcome, categorized as additional associated in the NOC-NANDA-I linkage for the diagnosis in question, its evolution was statistically significant in this study $(p=0.035)$. It is believed that the educational activities performed preoperatively contributed to the patients presenting moderate knowledge regarding the activities that they may or may not perform in the postoperative period, represented by the score of 3 in the NOC scale. In addition, in the institution under study, patients undergoing THA receive a manual from the nursing team with guidelines on the care needed after discharge(11). This resource assists in the compression of the surgery and in the care that should be performed at home. Researchers emphasize that combined clinical and educational interventions can help patients awaiting surgery ${ }^{(17)}$.

The Fall prevention behavior Nursing Outcome presented progressive improvement in the mean scores $(p<0.001)$ for the patients monitored. This result was applicable in clinical practice, considering that patient safety is the focus of the nursing care in this hospital. In addition, $17(80.9 \%)$ of the study patients were monitored by caregivers during the hospitalization, a factor that may have helped in fall prevention behavior(18).

Although none of the patients in this study suffered falls during the monitoring, the related literature highlights the need to establish evaluation and fall prevention programs after arthroplasty surgeries. This policy becomes imperative due to the risks presented by patients undergoing THA, who mostly have functional limitations and advanced age ${ }^{(19)}$. In the study sample, the NOC scores showed that the patients presented from moderate to frequent fall prevention behavior, demonstrated throughout the evaluations. Accordingly, it is understood that this preventive behavior is inherent to individuals, who assume a positive attitude towards their health, in order to reduce their susceptibility, avoid the subsequent emergence of diseases and thus preserve their integrity ${ }^{(20)}$.

Regarding the mean scores between the collectors, there were no statistically significant differences in the evaluations for any of the NOs. A study that compared the interobserver concordance of patients evaluated with the use of operational definitions for the clinical indicators of the Ineffective Breathing Patterns ND verified inconsistencies in the evaluations of those who did not use them ${ }^{(21)}$.

Thus, the monitoring of the progress of patients, through a standardized classification, can facilitate evidence-based practice, favoring the quality of care and comprehensiveness of documentation, through the use of internationally recognized nursing language systems, which are valid and applicable in different real clinical settings ${ }^{(22-25)}$.

\section{Conclusion}

The use of the NOC outcomes made it possible to demonstrate the clinical progression of orthopedic patients with Impaired Physical Mobility, as well and its applicability in this context. It was possible to observe the status of the diagnosis under study, from the scores of the outcomes contained in the functional health, perceived health, and patient knowledge domains on each evaluated day. In addition, through the comparison of the mean scores between the collectors, the consistency of the evaluations, using an instrument constructed for this purpose, could be seen. However, the small sample size, the coverage of the NOC and the possibility of choice of the outcomes for different populations hindered the validation using psychometric criteria common in scale validation studies, which limits the generalizability of these findings.

As implications for practice, the construction and validation of conceptual and operational definitions for specific contexts is suggested, as well as training for nursing teams. The development of these activities prior to the implementation of the NOC, may facilitate its use in clinical practice and encourage the evaluation of the effectiveness of interventions, through the monitoring of nursing care outcomes. The measurement of the time of evaluation of these results can maximize the impact of the applicability of these findings.

More studies on this topic are needed to establish the validity of the classification and of the possible comparisons with other populations and practice contexts.

\section{References}

1. Lenza M, Ferraz SB, Viola DCM, Filho RJG, Cendoroglo NM, Ferretti M. Epidemiology of total hip and knee replacement: a cross-sectional study. Einstein. 2013;11(2):197-202. 
2. Piano LPA, Golmia RP, Scheinberg M. Artroplastia total de quadril e joelho: aspectos clínicos na fase perioperatória. Einstein. 2010;8(3Pt1):350-3.

3. Portal Brasil (BR). Cinco estados recebem mutirão de cirurgia ortopédica. Brasília (DF). [página da Internet] 2012 [acesso em 18 maio 2014]. Disponível em: http:// www.brasil.gov.br/saude/2012/09/cinco-estadosrecebem-mutirao-de-cirurgia-ortopedica

4. Tay Swee Cheng R, Klainin-Yobas P, Hegney D, Mackey $S$. Factors relating to perioperative experience of older persons undergoing joint replacement surgery: an integrative literature review. Disabil Rehabil. 2014. [No prelo] Disponível em: http://informahealthcare. com/doi/abs/10.3109/09638288.2014.906663

5. Seganfredo DH, Almeida MA. Produção de conhecimento sobre resultados de enfermagem. Rev bras enferm. 2010;63(1):122-6.

6. Moorhead S, Johnson M, Maas ML, Swanson E. Classificação dos Resultados de Enfermagem - NOC. $4^{a}$ ed. Porto Alegre: Artmed; 2010.

7. NANDA International. Diagnósticos de enfermagem da NANDA: definições e classificação 2012 - 2014. Porto Alegre: Artmed; 2013. 606 p.

8. Bulechek GM, Dochterman J, Butcher H. Classificação das Intervenções de Enfermagem (NIC). $5^{a}$ ed. Porto Alegre: Artmed; 2010.

9. Alecrim MS, Strufaldi MB, Santiago CN, Freitas J, Maciel FG, Gianini M. Diagnósticos de Enfermagem nas complicações mais relevantes no pós-operatório da artroplastia total de quadril. Enferm Brasil. 2011;10(4):242-7.

10. Tastan S, Linch GCF, Keenan GM, Stifter J, McKinney $D$, Fahey $L$, et al. Evidence for the existing American Nurses Association-recognized standardized nursing terminologies: A systematic review. Int J Nurs Studies. 2014 [acesso em 18 Maio 2014]; (no prelo). Disponível em:http://download.journals.elsevierhealth.com/pdfs/ journals/0020-7489/PIIS0020748913003817.pdf

11. Hospital de Clínicas de Porto Alegre. Serviço de Ortopedia e Traumatologia, Serviço de Enfermagem Cirúrgica e Serviço de Enfermagem em Saúde Pública. Convivendo bem com prótese de quadril. Porto Alegre (RS): Hospital de Clínicas de Porto Alegre; 2013. Disponível em: http://www.hcpa.ufrgs.br/downloads/ Comunicacao/protese_quadril_completo.pdf

12. Gonzalez CM, Howe CM, Waters TR, Nelson A, Hughes, N. Recommendations for Vertical Transfer of a Postoperative Total Hip Replacement Patient (Bed to Chair, Chair to Toilet, Chair to Chair, or Car to Chair). J Orthopaedic Nurs. 2009;28(2S):S13-7.
13. Andrade LT, Chianca TCM. Validação de intervenções de enfermagem para pacientes com lesão medular e mobilidade física prejudicada. Rev bras enferm. 2013;66(5):688-93.

14. Slaven EJ. Prediction of Functional Outcome at Six Months Following Total Hip Arthroplasty. Phys Ther. 2012;92(11):1386-94.

15. Young AC, Buvanendran A. Pain management for total hip arthroplasty. J Surg Orthop Adv. 2014;23(1):1321.

16. Di Nubila MFS, Matarazzo CG, Lopes-Albers AD, Gobbi FCM. Avaliação de resultados subjetivos de pacientes submetidos a artroplastia total de quadril pelo questionário WOMAC. Einstein. 2011;9(3Pt1):313-8.

17. Wallis JA, Taylor NF. Pre-operative interventions (nonsurgical and non-pharmacological) for patients with hip or knee osteoarthritis awaiting joint replacement surgery - a systematic review and meta-analysis. Osteoarthritis Cartilage. 2011;19(12):1381-95.

18. Dykes PC, Carroll DL, Hurley AC, Benoit A, Middleton B. Why Do Patients in Acute Care Hospitals Fall? Can Falls be Prevented? J Nurs Adm. 2009 [acesso em 25 Maio 2014]; 39(6):299-304. Disponível em: http:// www.ncbi.nlm.nih.gov/pmc/articles/PMC3107706/pdf/ nihms259498.pdf

19. Monzón DG, Iserson $\mathrm{KV}$, Jauregui J, Musso $\mathrm{C}$, Piccaluga F, Buttaro M. Total Hip Arthroplasty for Hip Fractures: 5-Year Follow-Up of Functional Outcomes in the Oldest Independent Old and Very Old Patients. Geriatr Orthop Surg Rehabil. 2014 [acesso em 18 Maio 2014]; 5(1):3-8. Disponível em: http://www.ncbi.nlm. nih.gov/pmc/articles/PMC3962050/

20. Vitor AF, Araújo TL. Definições para o resultado de enfermagem comportamento de prevenção de quedas: uma revisão integrativa. Rev Eletr Enf. 2011;13(2):31322.

21. Silva VM, Lopes $M V$, de Araujo $T L$, Beltrão $B A$, Monteiro FP, Cavalcante TF, Moreira RP, Santos FA. Operational definitions of outcome indicators related to ineffective breathing patterns in children with congenital heart disease. Heart Lung. 2011;40(3):e70-7.

22. Oliveira ARS, Costa AGS, Freitas JG, Lima FET, Masceno MMC, Araujo TL. Validação clínica dos diagnósticos, intervenções e resultados de enfermagem: revisão narrativa da literatura. Rev enferm UERJ. 2013;21(1):113-20.

23. Whited K, Aiyagari V, Calderon-Arnulphi M, Cursio J, Pandey D, Hillmann M, et al. Standardized admission and discharge templates to improve documentation of The Joint Commission on Accreditation of Healthcare 
Organization performance markers. J Neurosci Nurs. 2010;42(4):225-8.

24. Lucena AF. The nursing process: interfaces with the hospital accreditation process. Rev Gaúcha Enferm. 2013;34(4):8-9.

25. Carvalho EC, Cruz DALM, Herdman TH. Contribuição das linguagens padronizadas para a produção do conhecimento, raciocínio clínico e prática clínica da Enfermagem. Rev bras enferm. 2013;66(spe):134-41. 